Open Access

\title{
What is the evidence base for diagnosing hypertension and for subsequent blood pressure treatment targets in the prevention of cardiovascular disease?
}

\author{
Claire L. Schwartz and Richard J. McManus*
}

\begin{abstract}
Diagnosing and treating hypertension plays an important role in minimising the risk of cardiovascular disease and stroke. Early and accurate diagnosis of hypertension, as well as regular monitoring, is essential to meet treatment targets. In this article, current recommendations for the screening and diagnosis of hypertension are reviewed. The evidence for treatment targets specified in contemporary guidelines is evaluated and recommendations from the USA, Canada, Europe and the UK are compared. Finally, consideration is given as to how diagnosis and management of hypertension might develop in the future.
\end{abstract}

Keywords: ABPM, Blood pressure, Hypertension diagnosis, Hypertension guidelines, Self-monitoring, Thresholds, Treatment targets

\section{Background}

Hypertension affects around $40 \%$ of the worldwide population aged over 25 years, and is estimated to be implicated in approximately half of the deaths from stroke or cardiovascular disease [1]. Early and accurate diagnosis is essential in order to appropriately manage hypertension and reduce these risks, but national and international surveys suggest that many people continue to have unrecognised or untreated hypertension, with variation between countries [2,3]. Here, the evidence on screening and diagnosis of hypertension is reviewed and consideration given as to optimum treatment targets for preventing cardiovascular disease in patients.

\section{What is the best way to diagnose hypertension?}

Traditionally, hypertension has been diagnosed using clinic blood pressure (BP) measurements, typically taking several readings on several occasions and then treating those whose mean BP is consistently above the diagnostic threshold [4-6]. However, since the advent of

\footnotetext{
* Correspondence: richard.mcmanus@phc.ox.ac.uk

Nuffield Department of Primary Care Health Sciences, National Institute for Health Research (NIHR) National School for Primary Care Research, University of Oxford, Oxford OX2 6GG, UK
}

(c) 2015 Schwartz and McManus. Open Access This article is distributed under the terms of the Creative Commons Attribution 4.0 International License (http://creativecommons.org/licenses/by/4.0/), which permits unrestricted use, distribution, and reproduction in any medium, provided you give appropriate credit to the original author(s) and the source, provide a link to the Creative Commons license, and indicate if changes were made. The Creative Commons Public Domain Dedication waiver (http://creativecommons.org/publicdomain/zero/1.0/) applies to the data made available in this article, unless otherwise stated.

both ambulatory blood pressure monitoring (ABPM) and self-measured blood pressure (SMBP), it has been recognised that measurements outside of a clinic environment are better correlated with long-term outcomes [7-11].

ABPM is widely regarded as the "gold standard" for BP measurement. For example, both the Dublin outcome study, involving 5,292 patients, and a metaanalysis of 7,030 individuals from the International Database of Ambulatory Blood Pressure in relation to Cardiovascular Outcome (IDACO) database, found that systolic and diastolic ABPM measurements significantly and independently predicted cardiovascular outcomes over and above clinic BP [12, 13]. Furthermore, the Ohasama study $(1,464$ subjects, general population, 6 - to 9-year follow-up), found that mean ambulatory pressure, especially mean daytime, was linearly related to stroke risk and was a stronger predictor than clinic BP [14]. Other measures of blood pressure, particularly nighttime pressure, have been suggested as superior but may not add much more in terms of prognosis than the 24-hour mean itself [15]. ABPM also allows identification of masked and white coat hypertension and is reproducible [16-19]. Masked hypertension carries significant 
cardiovascular risk [20], which is estimated to be similar to sustained hypertension [21, 22].

There is also strong evidence for the prognostic accuracy of SMBP over clinic BP. SMBP is a significantly stronger predictor of cardiovascular outcomes [11, 23, 24], stroke [25, 26] and target organ damage [24, 27] than clinic BP. A recent systematic review found that the association of SMBP with target organ damage was as strong as that from ABPM [28].

Very few studies have assessed SMBP, ABPM and clinic BP against each other for cardiovascular outcomes. Fagard et al. compared these three methods of BP measurement for predicting cardiovascular events over 10 years in 391 older patients [29]. The authors found that the prognostic value of self-monitoring and daytime ABPM were similar to office measurements in predicting cardiovascular outcomes, but the strongest independent predictor was nighttime ABPM.

In a systematic review, Hodgkinson et al. evaluated 20 studies that had made a hypertension diagnosis with clinic or home BP measurement compared to ABPM as reference standard [30]. Using a clinic diagnostic threshold of $140 / 90 \mathrm{mmHg}$ and ambulatory and selfmonitoring thresholds of $135 / 85 \mathrm{mmHg}$, the review found neither home nor clinic measurements to be sufficiently accurate compared to ABPM, although others have argued that BP differences for those with discordant ABPM and self-monitoring are small [31, 32]. Furthermore, only three SMBP studies were available at the time. Since then, a number of other studies have been reported, including Nasothimiou [31] and Nunan [33]. The former studied patients attending a hypertension clinic and recorded high diagnostic test performance for self- compared to ambulatory monitoring, whereas Nunan's paper reported high sensitivity and only modest specificity, but utilised a community-based cohort with a lower prevalence of sustained hypertension ( $54 \%$ versus $65 \%$ in untreated subjects).

Current diagnostic thresholds for out-of-office measurement are based on work by Head et al., which compared 8,575 ABPM measurements to contemporaneous clinic readings taken by trained staff [34]. They found that the equivalent daytime mean ABPM for an office measurement of $140 / 90 \mathrm{mmHg}$ was $4 / 3 \mathrm{mmHg}$ less, which led to an ABPM target of $135 / 85 \mathrm{mmHg}$. However, work by Niiranen et al. suggested that the thresholds for SMBP are different and systolic thresholds in particular may be too high [35]. Based on a hypertensive population, Niiranen et al. found that thresholds of $130 / 85$ and $145 / 90 \mathrm{mmHg}$ for stages 1 and 2 hypertension better predicted outcomes for cardiovascular events over an 8-year follow-up.

A strong argument for using out-of-office measures arises from the concept of masked hypertension, where patients have a normal or controlled clinic BP but an elevated out-of-office measurement. Diagnosis of this condition is important because patients can be untreated or undertreated putting them at greater risk of cardiovascular disease [21]. Banegas et al. analysed data from the Spanish Society of Hypertension ABPM registry [36]. Out of more than 14,000 patients, with treated and (apparently) controlled clinic BP, $31.1 \%$ had masked uncontrolled hypertension, with the most likely reason being poor control of nighttime BP. Both ABPM and SMBP offer a way to diagnose and manage masked hypertension, but only if performed routinely in those with normal clinic BP. Hence more work needs to be carried out to understand the best way to target patients appropriately and manage masked hypertension in the longer term.

The cost-effectiveness of routine out-of-office measurement in the diagnosis of hypertension was assessed in a modelling exercise undertaken as part of the development of the National Institute for Health and Care Excellence (NICE) hypertension guideline [37]. This showed that the additional costs of ABPM were more than offset by the increased precision in diagnosis, and hence it was more cost-effective than either office BP measurement or SMBP for all age and gender subgroups. Long-term costs (in terms of cardiovascular events and reduced need for follow-up) were reduced when using ABPM instead of office BP measurement. There are potential issues with ABPM, including availability and feasibility [5]. However, given the need for life-long treatment following a diagnosis of hypertension, these are arguably insufficient to prevent implementation - a fact underpinned by the recent Canadian recommendations [38].

New technologies may provide a useful interface between non-physician screening and primary care. Telemonitoring and electronic submission of readings are becoming more popular [39] and, with smartphones becoming ever more sophisticated, it seems likely that this will play a role in diagnosing and managing hypertension in the future. There is growing evidence that telemonitoring in combination with self-monitoring is more effective than usual care in reducing blood pressure [40] and is acceptable to patients [41]. However, it is not widely used in clinical practice. The barriers to using telemonitoring include the initial set-up costs and issues around reimbursement.

A recent randomised controlled trial (RCT) using telemonitoring in the UK found that the direct mean cost of systolic BP reduction was $£ 25.56 / \mathrm{mmHg}$ per patient compared to usual care [42]. Even though the telemonitoring intervention significantly reduced BP over 6 months, unless longer-term outcomes (cardiovascular events) are considered, the additional costs 
of telemonitoring may not be considered affordable. There are also differences between healthcare and telemonitoring systems, which can lead to apparently contradictory results, with some found to be costeffective [43-45] but others not [46].

Another barrier, particularly significant to the USA, is the need for uniform quality standards which drive reimbursement. There is a lack of acceptance that patientreported data meets quality measures, which stipulate that controls, such as face-to-face visits and physiologic measurements, adhere to certain specifications, for example nurse-only BP checks [47]. In theory, telemonitoring could fulfil these criteria and the American Telehealth Association is working to address such barriers and start implementing telehealth in primary care [48]. As the evidence base for using telemonitoring in primary care continues to expand, it is likely that we will start to see guidelines and standards for telemonitoring in the UK and Europe as well.

\section{When should patients have their BP measured?}

In addition to the method of screening for hypertension, the frequency of such screening is also important, but the evidence to underpin this is scarce. Piper et al. tried to confirm "the shortest interval in which clinically significant, diagnosed hypertension may develop" in their recent systematic review [49]. They found 43 studies had examined screening intervals and established the incidence of hypertension found in 1- to 5-year intervals. It was impossible to reach any firm conclusions due to heterogeneity in the study results, with mean incidence ranging from $2 \%$ to $28 \%$ over a 5 -year period [49]. It may be more helpful to consider when to rescreen on the basis of current BP. Five studies reported on the incidence of hypertension over a 5-year period for three categories of BP: optimum, <120/80 mmHg; normal, 120-129/80-84 mmHg; and high-normal, 130-139/85$89 \mathrm{mmHg}$ [50-54]. Meta-analysis showed increased incidence of hypertension with increasing baseline blood pressure, a six-fold increase between high-normal and optimum, and a very low rate in the latter case - of less than $10 \%$ in a 5 -year period [49]. The authors suggest that this highlights the need to identify subpopulations which may benefit from a more structured screening programme, including older people, overweight or obese patients, those with a high-normal BP and certain ethnic minority groups [49].

Whilst primary care remains the commonest setting for hypertension screening, there is growing evidence to suggest that community screening may help to reach greater numbers of patients. A comprehensive systematic review by Fleming et al. showed that screening has been undertaken in a range of locations, with pharmacies and mobile units the most successful settings assessed, albeit with a high level of heterogeneity [55]. However, only $16 \%$ of studies reported a referral to primary care following screening, of which a new hypertension diagnosis was made in a median of $44 \%$, suggesting that a joined-up approach is fundamental to the impact of such screening.

Novel primary care settings may also prove successful, such as optometry [56]. In the USA, screening for medical conditions in dentistry has been assessed as potentially acceptable to both patients and physicians $[57,58]$. More studies in this area are needed to establish how physician and non-physician screening could complement each other.

Recently, a group of primary care practices in the USA developed an algorithm for identifying patients at risk of hypertension from their electronic records [59]. The innovation was successful and has now been implemented in these practices. It is easy to see how this type of innovation could be used in calculating rescreening intervals for patients and also follow-up times after BP treatment intensification.

\section{Where and how are patients currently diagnosed?}

Since 2011, in the UK, guidelines from NICE have recommended that a raised clinic BP reading $(\geq 140$ / $90 \mathrm{mmHg}$ ) in an undiagnosed patient should be followed by confirmatory ABPM, unless $\mathrm{BP} \geq 180 / 110 \mathrm{mmHg}$ [37]. Home BP measurement can be used as an alternative if ABPM is not available or tolerated.

In comparison, the European Society of Hypertension (ESH) practice guidelines (2013) recommend that office $\mathrm{BP}$ remains the "gold standard" for screening, diagnosis and management of hypertension [60]. However, for diagnostic purposes they recommend that ABPM or home BP is used in the case of suspected white coat hypertension, masked hypertension, grade I hypertension $(\geq 140 / 90 \mathrm{mmHg})$ and high-normal BP, which can be interpreted as a broad recommendation for use.

The Canadian Hypertension Education Program (CHEP) have recently updated their recommendations for the diagnosis of hypertension to include the use of $\mathrm{ABPM}$ and home BP monitoring [61]. For any office BP measurement $>140 / 90 \mathrm{mmHg}$ but $<180 / 110 \mathrm{mmHg}$, out-of-office measurement should be used to rule out white coat hypertension. ABPM readings should be taken every 20-30 minutes during the day and every 30-60 minutes at night. At least 20 daytime readings and 7 nighttime readings are required to obtain an accurate average reading. Home BP should be measured using validated monitors that have met the standards set by the Association for the Advancement of Medical Instrumentation (AAMI). Hypertension diagnoses using home monitoring should be based on duplicate measurements taken morning and evening for a 7-day 
period, with the first day discarded. A diagnostic target of $\geq 135 / 85 \mathrm{mmHg}$ is recommended for all out-of-office measurements [38]. In the USA, the Eighth Joint National Committee (JNC 8) report updated the threshold for a diagnosis of hypertension in those aged 60 years and over, and those with diabetes or chronic kidney disease, but maintained previous recommendations on the use of clinic BP for routine diagnosis of hypertension [62]. More recent evidence reviews in America have recommended updating guidelines to include ABPM for all new diagnoses of hypertension and as a way of quickly diagnosing white coat or masked hypertension. Overall, the direction of travel in guidelines in Europe and North America is firmly towards greater use of outof-office measurement of BP in the diagnosis of hypertension $[49,63]$.

\section{What is the evidence for treatment targets in hypertension?}

Although it can be argued that the relationship between $\mathrm{BP}$ and cardiovascular risk is continuous, hypertension targets provide an essential management guide [64]. The Hypertension Optimal Treatment (HOT) trial, which compared three diastolic targets $(\leq 90 \mathrm{mmHg}, \leq 85 \mathrm{mmHg}$ and $\leq 80 \mathrm{mmHg}$ ), tried to provide definitive data and found no difference overall in the rate of cardiovascular events between targets [65]. Interestingly, there was a $51 \%$ reduction in cardiovascular events between the $\leq 90 \mathrm{mmHg}$ target group and $\leq 80 \mathrm{mmHg}$ target group in diabetic patients, highlighting the need to consider different targets depending on the level of cardiovascular risk. Furthermore, post hoc analyses suggested that the lowest incidence of cardiovascular events was at $82.6 \mathrm{mmHg}$, whilst the lowest mortality rate was at $86.5 \mathrm{mmHg}$, and the small differences in achieved BP between groups have been criticised [65]. The use of diastolic targets has declined more recently with the evidence that systolic BP carries the greatest risk for heart disease and stroke, and this is reflected in most current guidelines [66, 67].

Over the last decade, work to establish accurate BP targets for treatment has been ongoing. A comprehensive meta-analysis by Law et al. reported a fall in cardiovascular disease (CVD) events by $25 \%$, a reduction in heart failure by about $25 \%$ and in stroke by $33 \%$ for every $10 \mathrm{mmHg}$ drop in systolic BP and every $5 \mathrm{mmHg}$ drop in diastolic BP without a lower threshold, at least to $110 \mathrm{mmHg}$ systolic [68]. A recent individual patient data meta-analysis by the Blood Pressure Lowering Treatment Trialists' Collaboration included over 50,000 patients and showed that lowering BP provided a similar relative risk reduction for all levels of cardiovascular risk [69]. However, the absolute risk reduction increased as the level of cardiovascular risk increased. For every
1,000 patients with $>20 \%$ cardiovascular risk, 38 CVD events could be prevented over 5 years, whereas for every 1,000 patients with a $6 \%$ cardiovascular risk, 14 CVD events would be prevented. Therefore, patients at the highest risk stand to gain the most from having their BP lowered and arguably might benefit from lower targets [69]. Despite this, trials have failed to show benefit from intensive lowering of BP, particularly for older patients. The Valsartan in Elderly Isolated Systolic Hypertension (VALISH) study assessed a BP target of $<140 \mathrm{mmHg}$ against a more relaxed target of $\geq 140-150 \mathrm{mmHg}$ in patients aged 70 years or older [70]. After 3 years, the number of composite cardiovascular events between the two target groups was not significant, although rather counterintuitively the authors concluded that the more stringent target was safe to initiate in older patients [70]. The Japanese Trial to Assess Optimal Systolic Blood Pressure in Elderly Hypertensive Patients (JATOS), which looked at the optimum systolic BP target in elderly hypertensive patients, also found no difference in cardiovascular disease or renal failure between patients with a systolic pressure $\leq 140 \mathrm{mmHg}$ and those with a target $\leq 160 \mathrm{mmHg}$ [71]. There was also no difference in mortality or adverse events between the groups. However, as the endpoints of both these trials were less frequent than expected, both were ultimately underpowered to answer whether tighter $\mathrm{BP}$ control was in fact superior to a more relaxed BP target.

The modelling work of Port et al. contradicts the epidemiological and trial evidence $[64,72]$ finding that the risk of CVD, stroke and death is stable below a cut-off at the 70th centile, with age- and sex-dependent increases in risk above this [73]. According to the thresholds proposed by Port et al., patients with a BP of $155 \mathrm{mmHg}$ would not be treated. This suggestion has not been taken up internationally by guideline developers, other than for the elderly where the Hypertension in the Very Elderly Trial (HYVET) provided strong evidence for a similar treatment target [74], although Port's work has the potential merit of targeting treatment to younger high relative risk individuals.

Recent work examining the effectiveness of BP targets in a treated hypertension population of 398,419 has shown the presence of a J-shaped curve, where the highest rate of mortality came from lower and higher BP than the reference standard of $130-139 / 60-79 \mathrm{mmHg}$. The nadir for systolic and diastolic BP was 137/ $69 \mathrm{mmHg}$, but stratified analysis for patients with diabetes showed that the nadir was slightly lower at 131/ $69 \mathrm{mmHg}$, while patients $\geq 70$ years of age had a nadir of 140/70 mmHg [75]. This supports the need for different targets for different patient groups, but does suggest that recent rowing back from lower (especially systolic) targets in uncomplicated hypertension is probably justified. 
A recent Cochrane review in 2012 assessed the benefit of pharmacotherapy in patients with mild, uncomplicated hypertension (140-149 mmHg systolic and/or 90$99 \mathrm{mmHg}$ diastolic) [76]. For 7,080 participants, treatment with antihypertensive drugs compared to placebo did not lead to significant differences in the relative risk of total mortality, coronary heart disease, stroke or cardiovascular events, and withdrawals due to adverse events were increased by antihypertensive drugs [76]. This is reflected in the risk-based approach taken by NICE and the New Zealand guidelines in terms of only treating patients with stage 1 hypertension at higher risk and by JNC 8 , albeit controversially in their relaxation of targets for older people [37, 62, 77].

However, the time taken to bring patients to the optimum systolic target can also impact on mortality outcomes. Xu et al. investigated the time to intensification of treatment and the time to follow-up for new medications [78]. Delays in hypertension treatment intensification of 1.4 months or more and delays in BP follow-up after treatment intensification of 2.7 months or more resulted in increased likelihood of an acute cardiovascular event or death by 1.12 and 1.18 , respectively. However, a systolic target of $150 \mathrm{mmHg}$ performed similarly to one of $140 \mathrm{mmHg}$, with the greatest risk of cardiovascular events or death seen at systolic intensification targets of $160 \mathrm{mmHg}$ or more and a hazard ratio of at least 1.21 [78].

Earlier this year, Zanchetti et al. carried out a metaanalysis on 68 BP lowering trials to try and answer questions about the effectiveness of current thresholds [79]. They found that all-cause mortality, including stroke, cardiovascular, coronary heart disease and heart failure, were all significantly reduced by lowering systolic BP below $150 \mathrm{mmHg}$. With the exception of heart failure, outcomes could be further reduced by reducing systolic BP to $140 \mathrm{mmHg}$. Below this, only stroke was significantly reduced by decreasing systolic BP to $130 \mathrm{mmHg}$. Similarly, for diastolic BP, a significant reduction of cardiovascular outcomes could be seen at a cut-off of $<90 \mathrm{mmHg}$, but only significant reductions in stroke could be seen for a target of $<80 \mathrm{mmHg}$.

\section{Current target recommendations}

NICE reviewed three systematic reviews and 27 prognostic studies to develop their current treatment threshold recommendations [37]. The cut-off points for ABPM were set lower than those for clinic BP. Evidence for these thresholds came largely from work comparing clinic BP and ABPM to cardiovascular outcomes [80, 81]. The Pressioni Arteriose Monitorate e Loro Associazioni (PAMELA) trial was a landmark study in this area and the authors predicted that a clinic BP of $140 / 90 \mathrm{mmHg}$ was equivalent to a 24-hour ABPM of $125 / 80 \mathrm{mmHg}$ or a daytime ABPM of 130/85 mmHg [81]. However, this work was based on prognostic thresholds and there is very little evidence for comparable treatment targets between ABPM and clinic BP. As discussed above, Head et al. analysed clinic BP and ABPM measurements from patients referred to hypertension clinics across Australia [34, 80]. The treatment target recommendations for ABPM and SMBP (Table 1) from the NICE guidelines are largely based on this work.

NICE suggests an ABPM treatment target of $<135 /$ $85 \mathrm{mmHg}$ for patients below 80 years of age and an ABPM target of $<145 / 85 \mathrm{mmHg}$ for those patients over 80 years [37]. Currently, they are the only guidelines to specify a common treatment and management threshold for ABPM with the same thresholds assumed for home $\mathrm{BP}$ monitoring.

The ESH 2013 guidelines suggest a target of $<140 \mathrm{mmHg}$ for all patients under 80 years of age and a diagnostic target of $<90 \mathrm{mmHg}$. Diabetic patients should be treated to a diastolic target of $<85 \mathrm{mmHg}$. Patients over 80 years with a systolic BP $\geq 160 \mathrm{mmHg}$ should be treated to a target between 140 and $150 \mathrm{mmHg}$ according to the evidence [5].

The recent JNC 8 guideline recommended treating those between 18 and 60 years old to a target of 140/ $90 \mathrm{mmHg}$ [62]. However, for those patients above 60 years, they recommended a systolic treatment target of $<150 \mathrm{mmHg}$. This caused some controversy, but the committee argued that evidence from the trials they had considered found little benefit of tighter control leading to better outcomes [62]. However, many countered that these recommendations were based on a very small number of trials which passed the rigorous screening process, excluding evidence from meta-analysis, and meaning that this recommendation was almost entirely based on expert opinion [82].

\section{Conclusion and future directions}

Due to its diagnostic accuracy, ABPM seems set to assume greater prominence for the new diagnosis of hypertension - it is already in place in the NICE and arguably the ESH guidelines $[5,37]$ and there are strong recommendations for the USA and Canada to follow suit $[49,63]$. Less developed countries may reasonably continue with clinic measurement. It is likely that selfmonitoring will also feature strongly and this is seen in the latest Japanese guidance [83]. There is strong evidence for the use of out-of-office measurements to diagnose and manage patients with white coat and masked hypertension, with important implications for the appropriate targeting of treatment.

Outside of primary care, other health professionals, such as pharmacists, dentists and optometrists, are starting to have more of a role in monitoring BP. 
Table 1 Comparison of recommendations for diagnostic and treatment thresholds between NICE, ESH, JNC and CHEP guidelines

\begin{tabular}{|c|c|c|}
\hline Organisation & Year & Diagnostic threshold \\
\hline \multirow[t]{2}{*}{$\begin{array}{l}\text { UK National Institute for Health and } \\
\text { Care Excellence (NICE) }\end{array}$} & \multirow[t]{2}{*}{2011} & $\begin{array}{l}\text { OBPM diagnostic threshold: } \geq 140 / 90 \mathrm{~mm} \\
\text { (ABPM/HBPM diagnostic threshold: } \\
\geq 135 / 85 \mathrm{mmHg} \text { ) }\end{array}$ \\
\hline & & $\begin{array}{l}\text { OBPM Stage } 2 \text { Hypertension } \geq 160 / 100 \mathrm{~mm} \\
\text { (ABPM/HBPM: } \geq 150 / 95 \mathrm{mmHg} \text { ) }\end{array}$ \\
\hline \multirow[t]{2}{*}{ European Society of Hypertension (ESH) } & \multirow[t]{2}{*}{2013} & OBPM: $\geq 140$ and/or $\geq 90$ \\
\hline & & $\begin{array}{l}\text { (ABPM Daytime (or awake): } \geq 135 \text { and/or } \\
\geq 85 \mathrm{mmHg}, \text { ABPM Night-time (or asleep): } \\
\geq 120 \mathrm{and} / \text { or } \geq 70 \mathrm{mmHg}, \text { ABPM } 24-\mathrm{h} \text { : } \\
\geq 130 \text { and/or } \geq 80 \mathrm{mmHg}, \text { HBPM: } \geq 135 \\
\text { and/or } \geq 85 \mathrm{mmHg} \text { ) }\end{array}$ \\
\hline
\end{tabular}

Joint National Committee on Prevention, Detection, Evaluation and Treatment of Blood Pressure (JNC 7)

Joint National Committee on Prevention, Detection, Evaluation and Treatment of Blood Pressure (JNC 8)

Canadian Hypertension Education Program (CHEP)
2004 Stage 1 hypertension diagnosis should be confirmed within 2 months after initial elevated OBPM $\geq 140 / 90 \mathrm{mmHg}$

Stage 2 hypertension should be confirmed within $1 \mathrm{~m}$

$\geq 180 / 110 \mathrm{~mm} \mathrm{Hg}$ evaluate and treat immediately

(ABPM Daytime (or awake): $\geq 135 / 85$ mmHg, ABPM Night-time (or asleep): $\geq 120 / 75 \mathrm{mmHg}$ )

Routine blood pressure measurements should be taken

- at least once every 2 years for adults with $<120 / 80 \mathrm{mmHg}$

- every year for adults with 120-139/80-89 mmHg

2014 - Guidelines did not address diagnostic thresholds of hypertension.

- The supplementary material recommends averaging 2-3 measurements at each visit to establish a diagnosis of hypertension.

- Thresholds for pharmacological treatment were defined.

- HBPM and ABPM were not included.

2015 ABPM Daytime (or awake): $\geq 135 / 85 \mathrm{mmHg}$

ABPM 24-h: $\geq 130 / 80 \mathrm{mmHg}$

HBPM diagnostic threshold: $\geq 135 / 85 \mathrm{mmHg}$ )

OBPM diagnostic threshold:

$\geq 140 / 90 \mathrm{mmHg}$ averaged across two visits;

$\geq 160 / 110 \mathrm{mmHg}$ averaged across three visits;

or if $\geq 140 / 90 \mathrm{mmHg}$ averaged across five visits
Treatment threshold

All patients under 80 yrs: OBPM

$<140 / 90 \mathrm{mmHg}$ (ABPM/HBPM:

$<135 / 85 \mathrm{mmHg}$ )

Diabetes : OBPM $<140 / 80 \mathrm{mmHg}$ (or $<130 / 80 \mathrm{mmHg}$ if complications present)

Older $\geq 80$ yrs: OBPM $<150 / 90 \mathrm{mmHg}$ (ABPM/HBPM <145/85 mmHg)

All patients under $80 \mathrm{yrs}$ OBPM $<140 / 90 \mathrm{mmHg}$

Diabetes: OBPM <140/85 mmHg

High Risk Patients: OBPM

$<130 / 80 \mathrm{mmHg}$

Older $\geq 80$ yrs: OBPM $<150 / 90 \mathrm{mmHg}$

Non-diabetic patients: OBPM

$<140 / 90 \mathrm{mmHg}$

Diabetic/CKD patients: OBPM

$<130 / 80 \mathrm{mmHg}$
Age <60 yrs: OBPM $<140 / 90 \mathrm{mmHg}$

Diabetes No CKD: OBPM <140/90 mmHg

CKD present with or without diabetes: OBPM $<140 / 90 \mathrm{mmHg}$

Older $\geq 60$ years: OBPM $<150 / 90 \mathrm{mmHg}$

All ages < 80 yrs: OBPM $<140 / 90 \mathrm{mmHg}$ Diabetes: OBPM $<130 / 80 \mathrm{mmHg}$

Older $\geq 80$ yrs: OBPM $<150 \mathrm{mmHg}$

Abbreviations: OBPM office blood pressure measurement, $A B P M$ ambulatory blood pressure measurement, HBPM home blood pressure measurement, $C K D$ chronic kidney disease

There will need to be clear pathways set up between these organisations and primary care providers in order to follow-up cases of high BP readings [55]. Self-monitoring is also starting to be used for selfscreening [55] and we may see a role for this in patients identified as having high-normal BP. Robust diagnostic guidelines will be needed to advise both physicians and non-physicians how to obtain accurate out-of-office measurements. The use of smartwatches for health tracking may drive greater telemonitoring, but for the moment cuff-based measurements limit their use in hypertension. 
Measurement of blood pressure is well captured by the guidelines, but what is less clear is how to ensure adequate population screening. Further studies should seek to establish optimum rescreening intervals, alternative ways to gain full population coverage and methods to identify those at greatest risk.

Many trials have shown that controlling blood pressure is an important way of reducing heart disease and stroke $[68,74,84,85]$. Blood pressure targets are an essential clinical tool for guiding control of blood pressure. However, questions about the optimum targets remain, particularly for patient subpopulations, such as the elderly, those with high cardiovascular risk and certain ethnic groups [86]. Studies in this area should focus on the optimum BP threshold to initiate treatment, but also perhaps when to reduce treatment, particularly in the context of polypharmacy [87].

Overall, the mainstay of hypertension diagnosis and monitoring is likely to remain systematically identifying and then treating patients to fairly conventional targets, with use of out-of-office monitoring for both diagnosis and management. Ensuring physicians do not succumb to clinical inertia is probably as important as the actual methods and targets used [88].

\begin{abstract}
Abbreviations
AAMI: Association for the Advancement of Medical Instrumentation; ABPM: Ambulatory blood pressure monitoring; BP: Blood pressure; CHEP: Canadian Hypertension Education Program; CVD: Cardiovascular disease; ESH: European Society of Hypertension; HOT: Hypertension Optimal Treatment; HYVET: Hypertension in the Very Elderly Trial; IDACO: International Database of Ambulatory Blood Pressure in relation to Cardiovascular Outcome; JATOS: Japanese Trial to Assess Optimal Systolic Blood Pressure in Elderly Hypertensive Patients; JNC 8: Eighth Joint National Committee; NICE: National Institute for Health and Care Excellence; PAMELA: Pressioni Arteriose Monitorate e Loro Associazioni; RCT: Randomised controlled trial; SMBP: Self-measured blood pressure; VALISH: Valsartan in Elderly Isolated Systolic Hypertension.
\end{abstract}

\section{Competing interests}

RJM received blood pressure monitoring equipment for research from Lloyds Pharmacy and Omron. RJM also received expenses and an honorarium for speaking at the Japanese Society of Hypertension.

\section{Authors' contributions}

RJM and CLS jointly conceived the article following a commission. CLS wrote the first draft and both authors subsequently drafted the paper. Both authors read and approved the final version of the manuscript.

\section{Authors' information}

RJM is Professor of Primary Care at the Nuffield Department of Primary Care Health Sciences, University of Oxford, UK. CLS is Research Fellow at the Nuffield Department of Primary Care Health Sciences, University of Oxford, UK.

\section{Acknowledgements}

The authors acknowledge the helpful advice from the reviewers of this paper. This work was unfunded. RJM and CLS are funded through an NIHR Professorship (NIHR-RP-02-12-015) and their work is supported via an NIHR Programme Grant (RP-PG-1209-10051) and the NIHR Collaboration for Leadership in Applied Health Research and Care (CLAHRC) Oxford at Oxford Health NHS Foundation Trust. The views expressed in this paper are those of the authors and not necessarily of the NHS, the NIHR or the Department of Health.
Received: 13 July 2015 Accepted: 17 September 2015

Published online: 12 October 2015

\section{References}

1. Laslett LJ, Alagona Jr P, Clark 3rd BA, Drozda Jr JP, Saldivar F, Wilson SR, et al. The worldwide environment of cardiovascular disease: prevalence, diagnosis, therapy, and policy issues: a report from the American College of Cardiology. J Am Coll Cardiol. 2012;60:S1-49.

2. Townsend N, Williams J, Bhatnagar P, Wickramasinghe K, Rayner M. Cardiovascular disease statistics 2014. London: British Heart Foundation; 2014. Available from: https://www.bhf.org.uk/ /media/files/publications/ research/bhf_cvd-statistics-2014_web_2.pdf.

3. Joffres M, Falaschetti E, Gillespie C, Robitaille C, Loustalot F, Poulter N, et al. Hypertension prevalence, awareness, treatment and control in national surveys from England, the USA and Canada, and correlation with stroke and ischaemic heart disease mortality: a cross-sectional study. BMJ Open. 2013;3:e003423.

4. The National Institute for Health and Care Excellence (NICE). Clinical management of primary hypertension in adults. London: NICE; 2006.

5. Mancia G, Fagard R, Narkiewicz K, Redon J, Zanchetti A, Bohm M, et al. 2013 ESH/ESC Guidelines for the management of arterial hypertension: The Task Force for the management of arterial hypertension of the European Society of Hypertension (ESH) and of the European Society of Cardiology (ESC). Eur Heart J. 2013;34:2159-219.

6. Chobanian AV, Bakris GL, Black HR, Cushman WC, Green LA, Izzo Jr JL, et al. The Seventh Report of the Joint National Committee on Prevention, Detection, Evaluation, and Treatment of High Blood Pressure: the JNC 7 report. JAMA. 2003;289:2560-72.

7. Ohkubo T, Imai Y, Tsuji I, Nagai K, Watanabe N, Minami N, et al. Prediction of mortality by ambulatory blood pressure monitoring versus screening blood pressure measurements: a pilot study in Ohasama. J Hypertens. 1997;15:357-64.

8. Hansen TW, Jeppesen J, Rasmussen S, Ibsen H, Torp-Pedersen C. Ambulatory blood pressure monitoring and risk of cardiovascular disease: a population based study. Am J Hypertens. 2006;19:243-50.

9. Dolan E, Stanton AV, Thom S, Caulfield M, Atkins N, Mclnnes G, et al. Ambulatory blood pressure monitoring predicts cardiovascular events in treated hypertensive patients-an Anglo-Scandinavian cardiac outcomes trial substudy. J Hypertens. 2009;27:876-85.

10. Ward AM, Takahashi O, Stevens R, Heneghan C. Home measurement of blood pressure and cardiovascular disease: systematic review and metaanalysis of prospective studies. J Hypertens. 2012;30:449-56.

11. Nirranen TJ, Hanninen MR, Johansson J, Reunanen A, Jula AM. Homemeasured blood pressure is a stronger predictor of cardiovascular risk than office blood pressure: the Finn-Home study. Hypertension. 2010;55:1346-51.

12. Dolan E, Stanton A, Thijs L, Hinedi K, Atkins N, McClory S, et al. Superiority of ambulatory over clinic blood pressure measurement in predicting mortality: the Dublin outcome study. Hypertension. 2005;46:156-61.

13. Hansen TW, Kikuya M, Thijs L, Bjorklund-Bodegard K, Kuznetsova T, Ohkubo $T$, et al. Prognostic superiority of daytime ambulatory over conventional blood pressure in four populations: a meta-analysis of 7,030 individuals. J Hypertens. 2007;25:1554-64.

14. Ohkubo T, Asayama K, Kikuya M, Metoki H, Obara T, Saito S, et al. Prediction of ischaemic and haemorrhagic stroke by self-measured blood pressure at home: the Ohasama study. Blood Press Monit. 2004;9:315-20.

15. Hansen TW, Li Y, Boggia J, Thijs L, Richart T, Staessen JA. Predictive role of the nighttime blood pressure. Hypertension. 2011;57:3-10.

16. Verdecchia P. Reference values for ambulatory blood pressure and selfmeasured blood pressure based on prospective outcome data. Blood Press Monit. 2001;6:323-7.

17. Verdecchia P, O'Brien E, Pickering T, Staessen JA, Parati G, Myers M, et al. When can the practicing physician suspect white coat hypertension? Statement from the Working Group on Blood Pressure Monitoring of the European Society of Hypertension. Am J Hypertens. 2003;16:87-91.

18. Hodgkinson J, Wood S, Martin U, McManus R. ABPM is best for diagnosing hypertension in primary care. Practitioner. 2011;255:21-3. 2.

19. Ben-Dov IZ, Ben-Arie L, Mekler J, Bursztyn M. Reproducibility of white-coat and masked hypertension in ambulatory BP monitoring. Int J Cardiol. 2007;117:355-9,

20. Pickering TG, Davidson K, Gerin W, Schwartz JE. Masked hypertension. Hypertension. 2002;40:795-6. 
21. Angeli F, Reboldi G, Verdecchia P. Masked hypertension: evaluation, prognosis, and treatment. Am J Hypertens. 2010;23:941-8.

22. Cuspidi C, Sala C, Tadic M, Rescaldani M, Grassi G, Mancia G. Untreated masked hypertension and subclinical cardiac damage: a systematic review and meta-analysis. Am J Hypertens. 2015;28:806-13.

23. Asayama K, Thijs L, Brguljan-Hitij J, Niiranen TJ, Hozawa A, Boggia J, et al. Risk stratification by self-measured home blood pressure across categories of conventional blood pressure: a participant-level meta-analysis. PLoS Med. 2014;11:e1001591.

24. Fuchs SC, Mello RG, Fuchs FC. Home blood pressure monitoring is better predictor of cardiovascular disease and target organ damage than office blood pressure: a systematic review and meta-analysis. Curr Cardiol Rep. 2013;15:413.

25. Asayama K, Ohkubo T, Hara A, Hirose T, Yasui D, Obara T, et al. Repeated evening home blood pressure measurement improves prognostic significance for stroke: a 12-year follow-up of the Ohasama study. Blood Press Monit. 2009:14:93-8.

26. Asayama K, Ohkubo T, Kikuya M, Metoki H, Obara T, Hoshi H, et al. Use of 2003 European Society of Hypertension-European Society of Cardiology guidelines for predicting stroke using self-measured blood pressure at home: the Ohasama study. Eur Heart J. 2005:26:2026-31.

27. Mule G, Caimi G, Cottone S, Nardi E, Andronico G, Piazza G, et al. Value of home blood pressures as predictor of target organ damage in mild arterial hypertension. J Cardiovasc Risk. 2002;9:123-9.

28. Bliziotis IA, Destounis A, Stergiou GS. Home versus ambulatory and office blood pressure in predicting target organ damage in hypertension: a systematic review and meta-analysis. J Hypertens. 2012;30:1289-99.

29. Fagard RH, Van Den Broeke C, De Cort P. Prognostic significance of blood pressure measured in the office, at home and during ambulatory monitoring in older patients in general practice. J Hum Hypertens. 2005;19:801-7.

30. Hodgkinson J, Mant J, Martin U, Guo B, Hobbs FD, Deeks JJ, et al. Relative effectiveness of clinic and home blood pressure monitoring compared with ambulatory blood pressure monitoring in diagnosis of hypertension: systematic review. BMJ. 2011;342:d3621.

31. Nasothimiou EG, Tzamouranis D, Roussias LG, Stergiou GS. Home versus ambulatory blood pressure monitoring in the diagnosis of clinic resistant and true resistant hypertension. J Hum Hypertens. 2012;26:696-700.

32. Chrubasik-Hausmann S, Chrubasik C, Walz B, Monting JS, Erne P. Comparisons of home and daytime ambulatory blood pressure measurements. BMC Cardiovasc Disord. 2014;14:94.

33. Nunan D, Thompson M, Heneghan CJ, Perera R, McManus RJ, Ward A. Accuracy of self-monitored blood pressure for diagnosing hypertension in primary care. J Hypertens. 2015;33:755-62.

34. Head GA, Mihailidou AS, Duggan KA, Beilin LJ, Berry N, Brown MA, et al. Definition of ambulatory blood pressure targets for diagnosis and treatment of hypertension in relation to clinic blood pressure: prospective cohort study. BMJ. 2010;340:C1104

35. Niiranen TJ, Asayama K, Thijs L, Johansson JK, Ohkubo T, Kikuya M, et al. Outcome-driven thresholds for home blood pressure measurement: international database of home blood pressure in relation to cardiovascular outcome. Hypertension. 2013;61:27-34.

36. Banegas JR, Ruilope LM, de la Sierra A, de la Cruz JJ, Gorostidi M, Segura J, et al. High prevalence of masked uncontrolled hypertension in people with treated hypertension. Eur Heart J. 2014;35:3304-12.

37. The National Institute for Health and Care Excellence (NICE). Hypertension: clinical management of primary hypertension in adults. London: NICE; 2011.

38. Daskalopoulou SS, Rabi DM, Zarnke KB, Dasgupta K, Nerenberg K, Cloutier L, et al. The 2015 Canadian Hypertension Education Program recommendations for blood pressure measurement, diagnosis, assessment of risk, prevention, and treatment of hypertension. Can J Cardiol. 2015;31:549-68.

39. North F, Elrashidi MY, Ward WJ, Takahashi PY, Ebbert JO, Ytterberg KL, et al. Telemonitoring blood pressure by secure message on a patient portal: use, content, and outcomes. Telemed J E Health. 2015;32:630-6.

40. Purcell R, Mclnnes $S$, Halcomb EJ. Telemonitoring can assist in managing cardiovascular disease in primary care: a systematic review of systematic reviews. BMC Fam Pract. 2014;15:43.

41. Hallberg I, Ranerup A, Kjellgren K. Supporting the self-management of hypertension: Patients' experiences of using a mobile phone-based system. J Hum Hypertens. 2015. doi: 10.1038/jhh.2015.37
42. Stoddart A, Hanley J, Wild S, Pagliari C, Paterson M, Lewis S, et al. Telemonitoring-based service redesign for the management of uncontrolled hypertension (HITS): cost and cost-effectiveness analysis of a randomised controlled trial. BMJ Open. 2013;3. doi: 10.1136/bmjopen-2013-002681.

43. Kaambwa B, Bryan S, Jowett S, Mant J, Bray EP, Hobbs FR, et al. Telemonitoring and self-management in the control of hypertension (TASMINH2): a cost-effectiveness analysis. Eur J Prev Cardiol. 2014;21:1517-30.

44. Fukunaga $\mathrm{H}$, Ohkubo $T$, Kobayashi M, Tamaki $Y$, Kikuya M, Obara T, et al. Cost-effectiveness of the introduction of home blood pressure measurement in patients with office hypertension. J Hypertens. 2008;26:685-90.

45. Reed SD, Li Y, Oddone EZ, Neary AM, Orr MM, Grubber JM, et al. Economic evaluation of home blood pressure monitoring with or without telephonic behavioral self-management in patients with hypertension. Am J Hypertens. 2010:23:142-8.

46. Madsen LB, Christiansen T, Kirkegaard P, Pedersen EB. Economic evaluation of home blood pressure telemonitoring: a randomized controlled trial. Blood Press. 2011;20:117-25.

47. North F, Crane SJ, Takahashi PY, Ward WJ, Tulledge-Scheitel SM, Ytterberg K, et al. Telemedicine barriers associated with regional quality measures. Telemed J E Health. 2014;20:179-81.

48. American Telemedicine Association. Public policy. Available from: http://www.americantelemed.org/get-involved/public-policy-advocacy/ policy-issues.

49. Piper MA, Evans CV, Burda BU, Margolis KL, O'Connor E, Smith N, et al. Screening for high blood pressure in adults: a systematic evidence review for the US Preventive Services Task Force. Rockville, MD: Agency for Healthcare Research and Quality (US); 2014.

50. Kim J, Kim E, Yi H, Joo S, Shin K, Kim J, et al. Short-term incidence rate of hypertension in Korea middle-aged adults. J Hypertens. 2006;24:2177-82.

51. Kim SJ, Lee J, Nam CM, Jee SH, Park IS, Lee KJ, et al. Progression rate from new-onset pre-hypertension to hypertension in Korean adults. Circ J. 2011;75:135-40.

52. Matsuo T, Sairenchi T, Suzuki K, Tanaka K, Muto T. Long-term stable obesity increases risk of hypertension. Int J Obes (Lond). 2011;35:1056-62.

53. Vasan RS, Larson MG, Leip EP, Kannel WB, Levy D. Assessment of frequency of progression to hypertension in non-hypertensive participants in the Framingham Heart Study: a cohort study. Lancet. 2001;358:1682-6.

54. Yambe M, Tomiyama H, Yamada J, Koji Y, Motobe K, Shiina K, et al. Arterial stiffness and progression to hypertension in Japanese male subjects with high normal blood pressure. J Hypertens. 2007;25:87-93.

55. Fleming S, Atherton H, McCartney D, Hodgkinson J, Greenfield S, Hobbs FD, et al. Self-screening and non-physician screening for hypertension in communities: a systematic review. Am J Hypertens. 2015

56. Handler J, Mohan Y, Kanter MH, Reynolds K, Li X, Nguyen M, et al. Screening for high blood pressure in adults during ambulatory nonprimary care visits: opportunities to improve hypertension recognition. J Clin Hypertens (Greenwich). 2015;17:431-9.

57. Greenberg BL, Kantor ML, Jiang SS, Glick M. Patients' attitudes toward screening for medical conditions in a dental setting. J Public Health Dent. 2012;72:28-35

58. Greenberg BL, Thomas PA, Glick M, Kantor ML. Physicians' attitudes toward medical screening in a dental setting. J Public Health Dent. 2015;72:28-35.

59. Rakotz MK, Ewigman BG, Sarav M, Ross RE, Robicsek A, Konchak CW, et al. A technology-based quality innovation to identify undiagnosed hypertension among active primary care patients. Ann Fam Med. 2014;12:352-8.

60. ESH/ESC Task Force for the Management of Arterial Hypertension. 2013 Practice guidelines for the management of arterial hypertension of the European Society of Hypertension (ESH) and the European Society of Cardiology (ESC): ESH/ESC Task Force for the Management of Arterial Hypertension. J Hypertens. 2013;31:1925-38.

61. Hemmelgarn BR, McAllister FA, Myers MG, McKay DW, Bolli P, Abbott C, et al. The 2005 Canadian Hypertension Education Program recommendations for the management of hypertension: part 1- blood pressure measurement, diagnosis and assessment of risk. Can J Cardiol. 2005;21:645-56.

62. James PA, Oparil S, Carter BL, Cushman WC, Dennison-Himmelfarb C, Handler J, et al. 2014 evidence-based guideline for the management of high blood pressure in adults: report from the panel members appointed to the Eighth Joint National Committee (JNC 8). JAMA. 2014;311:507-20.

63. Cloutier L, Daskalopoulou SS, Padwal RS, Lamarre-Cliche M, Bolli P, McLean D, et al. A new algorithm for the diagnosis of hypertension in Canada. Can J Cardiol. 2015;31:620-30. 
64. MacMahon S, Peto R, Cutler J, Collins R, Sorlie P, Neaton J, et al. Blood pressure, stroke, and coronary heart disease. Part 1, Prolonged differences in blood pressure: prospective observational studies corrected for the regression dilution bias. Lancet. 1990;335:765-74.

65. Hansson L, Zanchetti A, Carruthers SG, Dahlof B, Elmfeldt D, Julius S, et al. Effects of intensive blood-pressure lowering and low-dose aspirin in patients with hypertension: principal results of the Hypertension Optimal Treatment (HOT) randomised trial. HOT Study Group. Lancet. 1998;351:1755-62.

66. Haider AW, Larson MG, Franklin SS, Levy D, Framingham HS. Systolic blood pressure, diastolic blood pressure, and pulse pressure as predictors of risk for congestive heart failure in the Framingham Heart Study. Ann Intern Med. 2003;138:10-6.

67. Borghi C, Dormi A, L'Italien G, Lapuerta P, Franklin SS, Collatina S, et al. The relationship between systolic blood pressure and cardiovascular risk-results of the Brisighella Heart Study. J Clin Hypertens (Greenwich). 2003;5:47-52.

68. Law MR, Morris JK, Wald NJ. Use of blood pressure lowering drugs in the prevention of cardiovascular disease: meta-analysis of 147 randomised trials in the context of expectations from prospective epidemiological studies. BMJ. 2009:338:b1665.

69. Collaboration Blood Pressure Lowering Treatment Trialists', Sundstrom J, Arima H, Woodward M, Jackson R, Karmali K, et al. Blood pressure-lowering treatment based on cardiovascular risk: a meta-analysis of individual patient data. Lancet. 2014;384:591-8.

70. Ogihara T, Saruta T, Rakugi H, Matsuoka H, Shimamoto K, Shimada K, et al. Target blood pressure for treatment of isolated systolic hypertension in the elderly: valsartan in elderly isolated systolic hypertension study. Hypertension. 2010;56:196-202.

71. JATOS Study Group. Principal results of the Japanese trial to assess optimal systolic blood pressure in elderly hypertensive patients (JATOS). Hypertens Res. 2008;31:2115-27.

72. Wald NJ, Law MR. A strategy to reduce cardiovascular disease by more than $80 \%$. BMJ. 2003:326:1419.

73. Port S, Demer L, Jennrich R, Walter D, Garfinkel A. Systolic blood pressure and mortality. Lancet. 2000;355:175-80.

74. Beckett NS, Peters R, Fletcher AE, Staessen JA, Liu L, Dumitrascu D, et al. Treatment of hypertension in patients 80 years of age or older. N Engl J Med. 2008:358:1887-98.

75. Sim JJ, Shi J, Kovesdy CP, Kalantar-Zadeh K, Jacobsen SJ. Impact of achieved blood pressures on mortality risk and end-stage renal disease among a large, diverse hypertension population. J Am Coll Cardiol. 2014:64:588-97.

76. Diao D, Wright JM, Cundiff DK, Gueyffier F. Pharmacotherapy for mild hypertension. Cochrane Database Syst Rev. 2012:8:CD006742.

77. New Zealand Guidelines Group. New Zealand Primary Care Handbook 2012. Cardiovascular disease risk assessment. 3rd edition, updated 2013 Wellington: New Zealand Guidelines Group; 2013. Available from: http:// www.health.govt.nz/publication/new-zealand-primary-care-handbook-2012.

78. Xu W, Goldberg SI, Shubina M, Turchin A. Optimal systolic blood pressure target, time to intensification, and time to follow-up in treatment of hypertension: population based retrospective cohort study. BMJ. 2015;350:h158.

79. Zanchetti A, Thomopoulos C, Parati G. Randomized controlled trials of blood pressure lowering in hypertension: a critical reappraisal. Circ Res. 2015;116:1058-73.

80. Kikuya M, Hansen TW, Thijs L, Bjorklund-Bodegard K, Kuznetsova T, Ohkubo T, et al. Diagnostic thresholds for ambulatory blood pressure monitoring based on 10-year cardiovascular risk. Circulation. 2007;115:2145-52.

81. Sega R, Facchetti R, Bombelli M, Cesana G, Corrao G, Grassi G, et al. Prognostic value of ambulatory and home blood pressures compared with office blood pressure in the general population: follow-up results from the Pressioni Arteriose Monitorate e Loro Associazioni (PAMELA) study. Circulation. 2005;111:1777-83.

82. Reisin E, Harris RC, Rahman M. Commentary on the 2014 BP guidelines from the panel appointed to the Eighth Joint National Committee (JNC 8). J Am Soc Nephrol. 2014;25:2419-24.

83. Ogihara T, Kikuchi K, Matsuoka H, Fujita T, Higaki J, Horiuchi M, et al. The Japanese Society of Hypertension Guidelines for the Management of Hypertension (JSH 2009). Hypertens Res. 2009;32:3-107.

84. Verdecchia P, Staessen JA, Angeli F, de Simone G, Achilli A, Ganau A, et al. Usual versus tight control of systolic blood pressure in non-diabetic patients with hypertension (Cardio-Sis): an open-label randomised trial. Lancet. 2009;374:525-33.

85. Turnbull F. Effects of different blood-pressure-lowering regimens on major cardiovascular events: results of prospectively-designed overviews of randomised trials. Lancet. 2003;362:1527-35.

86. Andersson C, Vasan RS. Lower is not always better? Blood pressure treatment targets revisited. J Am Coll Cardiol. 2014;64:598-600.

87. Scott IA, Hilmer SN, Reeve E, Potter K, Le Couteur D, Rigby D, et al. Reducing inappropriate polypharmacy: the process of deprescribing. JAMA Intern Med. 2015;175:827-34.

88. Phillips LS, Branch WT, Cook CB, Doyle JP, El Kebbi IM, Gallina DL, et al. Clinical inertia. Ann Intern Med. 2001;135:825-34

\section{Submit your next manuscript to BioMed Central and take full advantage of:}

- Convenient online submission

- Thorough peer review

- No space constraints or color figure charges

- Immediate publication on acceptance

- Inclusion in PubMed, CAS, Scopus and Google Scholar

- Research which is freely available for redistribution 